\title{
A Polymorphic Mutation, c.-3279T $>$ G, in the UGT1A1 Promoter Is a Risk Factor for Neonatal Jaundice in the Malay Population
}

\author{
SURINI YUSOFF, ATSUKO TAKEUCHI, CHITOSE ASHI, MASAKO TSUKADA, NUR H. MA'AMOR, BIN A. ZILFALIL, \\ NARAZAH M. YUSOFF, TSUTOMU NAKAMURA, MIDORI HIRAI, INDRA S.K. HARAHAP, GUNADI, MYEONG J. LEE, \\ NORIYUKI NISHIMURA, YUTAKA TAKAOKA, SATORU MORIKAWA, ICHIRO MORIOKA, NAOKI YOKOYAMA, \\ MASAFUMI MATSUO, HISAHIDE NISHIO, AND HANS VAN ROSTENBERGHE
}

\begin{abstract}
Departments of Community Medicine and Social Healthcare Science [S.Y., I.S.K.H., G., M.J.L., N.N., S.M., H.N.], Pediatrics [S.Y., N.N., S.M., I.M., N.Y., M.M., H.N.], Hospital Pharmacy [T.N., M.H.], and Division of Applied Genome Science and Bioinformatics [Y.T.], Kobe University Graduate School of Medicine, Kobe 650-0017, Japan; Department of Pediatrics [S.Y., N.H.M., H.V.R.], University Sains Malaysia, Kelantan 16150, Malaysia; Kobe Pharmaceutical University [A.T., C.A., M.T.], Kobe 658-8558, Japan; Human Genome Center [B.A.Z.], University Sains Malaysia, Kelantan 16150; Advanced Medical and Dental Institute [N.M.Y.], University Sains Malaysia, Pulau Pinang 11800, Malaysia
\end{abstract}

\begin{abstract}
The uridine diphosphoglucuronate-glucuronosyltransferase 1A1 (UGT1A1) gene encodes the enzyme responsible for bilirubin glucuronidation. To evaluate the contribution of UGT1A1 promoter mutations to neonatal jaundice, we determined the genotypes of c.-3279T $>\mathrm{G}$, c.-3156G $>\mathrm{A}$, and A(TA)7TAA in Malay infants with neonatal jaundice (patients) and in infants without neonatal jaundice (controls). In our population study, only c.$3279 \mathrm{~T}>\mathrm{G}$ was associated with neonatal jaundice. The genotype distributions between both groups were significantly different ( $p=$ 0.003): the frequency of homozygosity for c.-3279G was much higher in patients than those in controls. Allele frequency of c.$3279 \mathrm{G}$ was significantly higher in patients than those in controls ( $p=$ 0.006 ). We then investigated changes in transcriptional activity because of c.-3279T $>$ G. Luciferase reporter assay in HepG2 cells demonstrated that transcriptional activity of the c.-3279G allele was significantly lower than that of the c.-3279T allele in both the absence and presence of bilirubin. Luciferase reporter assay in COS-7 cells elucidated that c.-3279T $>\mathrm{G}$ modified the synergistic effects of the nuclear factors associated with transcriptional machinery. In conclusion, the c. $-3279 \mathrm{~T}>\mathrm{G}$ mutation in the UGT1Al promoter is a genetic risk factor for neonatal jaundice. (Pediatr Res 67: 401-406, 2010)
\end{abstract}

$\mathrm{T}^{\mathrm{s}}$ he uridine diphospho (UDP)-glucuronate-glucuronosyltransferase 1A1 (UGTIAl) gene encodes bilirubin UDPglucuronosyltransferase (UGT1A1), which is the enzyme responsible for bilirubin glucuronidation. A decrease in UGT1A1 activity leads to unconjugated hyperbilirubinemia. Inherited UGTIAl deficiencies because of UGTIAl mutations are classified into three forms based on clinical severity: Crigler-Najjar syndrome type 1 ( $\mathrm{CN}-1$, a severe form), Crigler-Najjar syndrome type 2 (CN-2, an intermediate form), and Gilbert's syndrome (GS, a mild form) $(1,2)$. Such inherited UGT1Al deficiencies may cause neonatal jaundice.

Received July 30, 2009; accepted December 15, 2009

Correspondence: Hisahide Nishio, M.D., Ph.D., Department of Community Medicine and Social Healthcare Science, Kobe University Graduate School of Medicine, 7-5-1 Kusunoki-cho, Chuo-ku, Kobe 650-0017, Japan; e-mail: nishio@med.kobe-u.ac.jp

Supported by grants from the Ministry of Science, Culture, and Sports of Japan (Research Project Number: 15406036) and from the Ministry of Science, Technology and Innovation (MOSTI) eScience Fund of Malaysia (Research Project Number: 06-0105-SF0166).
A mutant TATA box with an additional TA insertion, $\mathrm{A}$ (TA)7TAA, was first found in patients with $\mathrm{CN}-1, \mathrm{CN}-2$, and GS (3-5). GS with homozygosity for A(TA)7TAA accelerates or prolongs neonatal jaundice (6). This mutation is frequently observed in whites and Africans (7). Another GScausing gene mutation, c. $211 \mathrm{G}>\mathrm{A}$, is frequent in the East Asian population (8). The c. $211 \mathrm{G}>\mathrm{A}$ mutation causes an amino acid change, glycine to arginine at codon 71 .

Recently, polymorphic mutations, c.-3279T $>\mathrm{G}$ and c.$3156 \mathrm{G}>\mathrm{A}$, were identified in the UGTIAl promoter region $(9,10)$. The c. $-3279 \mathrm{~T}>\mathrm{G}$ mutation is located in the phenobarbital responsive enhancer module (gtPBREM), which is activated by a nuclear receptor, constitutive androstane receptor (CAR) (11). Sugatani et al. (9) showed using luciferase reporter assay that mutant gtPBREM with c.-3279T $>$ G decreases the transcriptional activity of the UGTIAl promoter by $60 \%$. The c. $-3156 \mathrm{G}>\mathrm{A}$ mutation is located between the gtPBREM and TATA box. A haplotype analysis showed that there is a high extent of linkage disequilibrium between c.-3156G $>$ A and A(TA)7TAA $(10,12)$. However, it is unknown whether c.-3156G $>$ A reduces the transcriptional activity of the UGT1Al promoter.

Although several studies of the A(TA)7TAA and c. $211 \mathrm{G}>\mathrm{A}$ mutations in the Southeast Asian population have been reported $(13,14)$, the c. $-3279 \mathrm{~T}>\mathrm{G}$ and c.-3156G $>\mathrm{A}$ mutations have never been examined in this population. Therefore, we determined the genotypes of the mutations, c. $-3279 \mathrm{~T}>\mathrm{G}$, c.-3156G $>\mathrm{A}$, and A(TA)7TAA, in Malay infants with or without neonatal jaundice to evaluate the contribution of the mutations of the UGTIAl promoter to the development of neonatal jaundice. In addition, we conducted a luciferase reporter assay with gtPBREM with or without

\footnotetext{
Abbreviations: AhR, human aryl hydrocarbon receptor; Arnt, human aryl hydrocarbon receptor nuclear translocator; CAR, human constitutive androstane receptor; GS, Gilbert's syndrome; gtPBREM, Phenobarbital responsive enhancer module in UGT1A1; RXR, human retinoid X receptor $\alpha$; UGT1A1, uridine diphosphoglucuronate-glucuronosyltransferase $1 \mathrm{~A} 1$
} 
c.-3279T $>\mathrm{G}$, to examine the effect of this mutation on transcriptional activity of the UGTIAl gene.

\section{SUBJECTS AND METHODS}

Subjects. In Kelantan, Malaysia, the Malays are the dominant population. Based on data of the Neonatal Ward at University Sains Malaysia (USM) Hospital in Kelantan, the overall rate of neonatal jaundice is $\sim 10 \%$ in Malay infants. In this study, 136 Malay infants in USM hospital with a gestational age of $>37 \mathrm{wk}$ and birth weights of $>2500 \mathrm{~g}$ were enrolled. Written informed consent was obtained from their parents. The subjects were divided into two groups: the jaundice group $(n=66)$ and control group $(n=70)$. A serum bilirubin (total) concentration of $>15 \mathrm{mg} / \mathrm{dL}(250 \mu \mathrm{M})$ within the first week after birth was defined as neonatal jaundice.

Infants fulfilling any of the following criteria were excluded from the study as follows: prematurity, presence of gross congenital malformations, Coombs-positive hemolytic anemia, birth trauma causing extravasation of blood (such as cephalohematoma or subaponeurotic hemorrhage), polycythemia, maternal diabetes, positive serology for viral hepatitis, or evidence of sepsis or asphyxia. Three infants with glucose-6-phosphate dehydrogenase (G6PD) deficiency and three infants with Southeast Asian ovalocytosis (SAO) were included in the jaundice group, but there were no infants with G6PD deficiency or SAO in controls. However, information on $\mathrm{ABO}$ and $\mathrm{Rh}$ blood types was not available in all subjects. This study was approved by the ethical committees of USM and Kobe University.

Detection of c.-3279T $>G$, c.-3156G $>A$, and A(TA)7TAA mutations. Genomic DNA was extracted from whole blood of the infants. To detect the c. $-3279 \mathrm{~T}>\mathrm{G}$ and c.-3156G $>$ A mutations, we conducted a combination method of semi-nested PCR and competitive oligonucleotide priming (COP)PCR. Semi-nested PCR can avoid unexpected amplification, and the COPPCR method with a short primer can detect a single nucleotide change (15). The primer sequences are listed in Figure 1. The first round of PCR amplified the target region including nucleotide positions c.-3279 and c.-3156, and the second round of PCR specifically amplified fragments with c.-3279T, c.-3279G, c.-3156G, and c.-3156A. In the second round, COP-PCR was conducted with a common forward primer used in the first round PCR and a reverse primer, which specifically bound to one of the variant nucleotides. The annealing temperatures of COP-PCR were as follows: $42^{\circ} \mathrm{C}$ for c.-3279T, $44^{\circ} \mathrm{C}$ for c. $-3279 \mathrm{G}, 30^{\circ} \mathrm{C}$ for c. $-3156 \mathrm{G}$, and $32^{\circ} \mathrm{C}$ for c. $-3156 \mathrm{~A}$. To confirm the COP-PCR, we sequenced all of the amplified fragments of the first round PCR by a dye-terminator automated sequencing method. To detect the A(TA)7TAA mutation, we determined the PCR fragment length as described previously (13).

Haplotype analysis. The UGT1A1 haplotypes were statistically inferred using an algorithm based on Bayesian inference, PHASE version 2.1.1 (http://www.stat.washington.edu/stephens), with a fair degree of precision.

\begin{tabular}{|c|c|c|c|c|c|}
\hline \multicolumn{2}{|c|}{$\begin{array}{l}\text { A } \\
\text { UGT1A1 Promoter }\end{array}$} & $\begin{array}{c}\text { c. }-3563 \\
\vdots \\
\end{array}$ & $\begin{array}{c}\text { c.-3279 } \\
\vdots\end{array}$ & $\begin{array}{c}c .-3156 \\
\vdots\end{array}$ & $\begin{array}{c}c .3105 \\
\vdots \\
\end{array}$ \\
\hline \multicolumn{2}{|c|}{$\begin{array}{l}\text { First Round PCR } \\
\text { (common) }\end{array}$} & $\mathrm{A} \Longleftrightarrow$ & & & $\rightleftarrows B$ \\
\hline \multicolumn{2}{|c|}{$\begin{array}{l}\text { Second Round PCR } \\
\text { (c. } 32797>G) \\
\text { (c. }-3156 \mathrm{G}>\mathrm{A})\end{array}$} & $\begin{array}{l}A \Longleftrightarrow \\
A \Longleftrightarrow\end{array}$ & C-1/C-2 & \\
\hline \multicolumn{6}{|l|}{ B } \\
\hline PCR & Type & Name & \multicolumn{3}{|l|}{ Sequence } \\
\hline \multirow{2}{*}{$\begin{array}{l}\text { First Round } \\
\text { PCR }\end{array}$} & Forward & Primer A (common) & \multicolumn{3}{|c|}{ 5'-CAC TCAATT CCAAGG GGAAA-3' } \\
\hline & Reverse & Primer B (outer) & \multicolumn{3}{|c|}{ 5'-AGT CCT CTG CCT TGC TCT CA-3' } \\
\hline \multirow{3}{*}{$\begin{array}{l}\text { Second } \\
\text { Round PCR } \\
\text { for } \\
\text { c.-3279T>G }\end{array}$} & Forward & Primer A (common) & \multicolumn{3}{|c|}{ 5-CAC TCAATT CCAAGG GGAAA-3' } \\
\hline & Reverse & Primer C-1 (inner for c.-3279T) & \multicolumn{3}{|c|}{ 5'-GTT CA_AACT G-3' } \\
\hline & & Primer C-2 (inner for c.-3279G) & \multicolumn{3}{|c|}{ 5'-GTT CAC ACT G-3' } \\
\hline \multirow{3}{*}{$\begin{array}{l}\text { Second } \\
\text { Round PCR } \\
\text { for } \\
\text { c. }-3156 \mathrm{G}>\mathrm{A}\end{array}$} & Forward & Primer A (common) & \multicolumn{3}{|c|}{ 5'-CAC TCAATT CCAAGG GGAAA-3' } \\
\hline & Reverse & Primer D-1 (inner for c.-3156G) & \multicolumn{3}{|c|}{ 5'-CTG TCC $\underline{A A G}$ CTC-3' } \\
\hline & & Primer D-2 2 inner for c. $3156 \mathrm{~A}$ ) & \\
\hline
\end{tabular}

Figure 1. Semi-nested PCR was used to detect c.-3279T $>$ G and c.-3156G $>A$ mutations in UGT1A1. A, Primer locations. The first PCR amplified the region of interest, including nucleotide positions c.-3279 and c.-3156, and the second PCR specifically amplified fragments with c.-3279T, c.-3279G, c.-3156G, and c.-3156A. $B$, Primer sequences. The length of nucleotide-specific reverse primers used in the second PCR was only 11-12 mer. Such short primers enabled nucleotide-specific amplification.

\begin{tabular}{|c|c|c|c|}
\hline $\begin{array}{l}\text { pgtPBREM } \\
\text { (-3279T) }\end{array}$ & gtPBREM(-3279T) & Mini-TK & LUC \\
\hline pgtPBREM & gtPBREM(-3279G) & Mini-TK & LUC \\
\hline
\end{tabular}

Figure 2. Construction map of pgtPBREM (gtPBREM-pGL2-Basic-miniTK plasmid). The 290-bp amplified UGT1A1 PBREM fragments (gtPBREM) with c.-3279T and c.-3279G were inserted into a pGL2-Basic vector with a minimum HSV-tyrosine kinase promoter sequence (Mini-TK). LUC, luciferase gene (firefly).

The haplotypes were inferred by running PHASE for a total of 10 times, and the relative SD of their frequencies was $5 \%$ or less of the mean value $(16,17)$.

Preparation of expression vectors. The gtPBREM-TK-firefly luciferase expression plasmid was prepared according to the method of Sugatani et al. (9,11). The PCR-amplified UGT1A1 PBREM fragments (gtPBREM) with c.-3279T and c.-3279G (290 bp) were inserted into a luciferase reporter plasmid, pGL2-Basic-miniTK (pGL2-Basic vector with a minimum HSVtyrosine kinase promoter sequence). These gtPBREM-TK-firefly luciferase expression plasmids were designated as "pgtPBREM(-3279T)" and "pgtPBREM(-3279G)." The construct maps of pgtPBREMs are presented in Figure 2.

The human CAR expression plasmid, pCAR, was prepared using Gateway Technology (Invitrogen/Life Technologies Corporation, CA). The CAR cDNA sequence was obtained by PCR amplification using a human liver cDNA library (BioChain Institute, Inc., CA). The human retinoid $X$ receptor $\alpha$ (RXR) expression plasmid, pRXR, was kindly provided by Dr. Ron M. Evans (The Salk Institute for Biological Studies, CA). The human aryl hydrocarbon receptor $(\mathrm{AhR})$ and human aryl hydrocarbon receptor nuclear translocator (Arnt) expression plasmids, pAhR and pArnt, were kindly provided by Dr. Susan Moran and Dr. Christopher Bradfield (McArdle Laboratory for Cancer Research, University of Wisconsin-Madison Medical School, WI). All expression vectors were sequenced by dye-terminator automated sequencing as described above.

Transcriptional activity assay. In this study, the response of mutant pgtPBREM to bilirubin was determined with HepG2 cells, and overexpression effects of "CAR and RXR," "AhR and Arnt," and "CAR, RXR, AhR, and Arnt" were examined in COS-7 cells.

The gtPBREM fragment is a composite regulatory element containing the multiple binding sites, gtNR1 (for nuclear receptors overexpressed in the cells in this study, CAR and RXR), xenobiotic responsive element (XRE; for AhR and Arnt), and NR3 (for CAR) $(12,18,19)$.

In the first assay, the HepG2 cells $\left[2 \times 10^{5}\right.$ cells in Minimum Essential Medium (MEM)] were cotransfected with pgtPBREM plasmid $(0.75 \mu \mathrm{g})$ and phRL (sea pansy) plasmid $(0.1 \mu \mathrm{g})$ (Promega Corporation, WI) using Lipofectamine 2000 (Invitrogen/Life Technologies Corporation). Twenty-four hours after transfection, bilirubin $(15 \mu \mathrm{M})$ was added to the MEM growing medium. The cells were then harvested after an additional $24 \mathrm{~h}$ of culture in the presence of bilirubin.

In the second assay, the COS-7 cells $\left(2 \times 10^{5}\right.$ cells in MEM) were cotransfected with pgtPBREM(-3279T) or pgtPBREM(-3279G) plasmids $(0.75 \mu \mathrm{g}), \mathrm{pAhR}+\mathrm{pArnt}$ plasmids $(0.25 \mu \mathrm{g}$ each $)$ and/or pCAR + pRXR plasmids $(0.25 \mu \mathrm{g}$ each), and phRL plasmid $(0.01 \mu \mathrm{g})$ (Promega, Madison, WI) using Lipofectamine 2000. The cells were harvested $48 \mathrm{~h}$ after transfection. Transcriptional activity was measured simultaneously using the dualluciferase reporter assay system, in which sea pansy-luciferase activity of the phRL plasmid was used as an internal control for the transfection efficiency of pgtPBREM plasmids.

Statistical analysis. The allele frequencies were examined for HardyWeinberg equilibrium by $\chi^{2}$ and Fisher's exact tests. The differences in genotype and allele frequencies between the neonatal jaundice and control groups were also examined using the $\chi^{2}$ test and Fisher's exact test. Experiments were repeated in triplicate in the transcriptional activity assay. The transcriptional activities were compared by $t$ tests. $p$ values of $<0.05$ were considered significant.

\section{RESULTS}

PCR-based techniques for mutation detection. The second round PCR (COP-PCR) specifically amplified the fragments with c.-3279T or c.-3279G (221 bp) and the fragments with 
c.-3156G or c.-3156A (334 bp). The gel electrophoresis clearly separated each genotype (Fig. 3). The sequencing data were consistent with the PCR results.

To detect the TATA box mutation, A(TA)7TAA, we determined the length of the PCR fragment of the UGTIAl promoter including the TATA box according to the GeneScan method described elsewhere (13). GeneScan analysis showed two types of fragments: a 90-bp fragment with the normal TATA box A(TA)6TAA and a 92-bp fragment with the mutated TATA box A(TA)7TAA (Fig. 3).

c.-3279T>G, c.-3156G $>A$, and A(TA)7TAA mutations. In Malay infants, c.-3156A was always found with A(TA)7TAA, suggesting a close linkage between them. However, there was not a close linkage between c.-3279G and c.-3156A, or between c.-3279G and A(TA)7TAA. These findings were confirmed by haplotype analysis using PHASE software (see below).

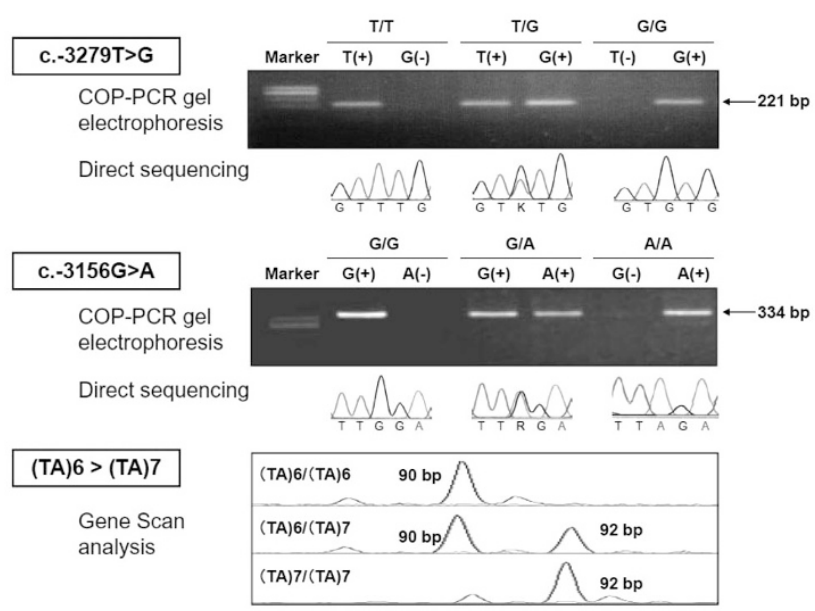

Figure 3. Detection of c.-3279T $>$ G, c.-3156G $>$ A, and A(TA)7TAA. Two percent agarose gel electrophoresis of COP-PCR products was used to show each genotype for c.-3279T $>$ G and c.-3156G $>$ A. Phi-X 174 DNA-HaeIII digest was used as a marker. To confirm the COP-PCR data, we performed direct sequencing of the first round PCR products. "K" denotes T and G and " $R$ " denotes $\mathrm{G}$ and $\mathrm{A}$ in the sequencing data. GeneScan analysis was used to show each genotype for A(TA)6TAA $>$ A(TA)7TAA. (TA)6, A(TA)6TAA; (TA)7, A(TA)7TAA.
Genotype distributions based on the nucleotide at c.-3279 are shown in Table 1 . The genotype distributions of jaundice and control groups did not shift from Hardy-Weinberg equilibrium. The genotype distributions between both groups were significantly different $(p=0.003)$ : the frequency of homozygosity for c.-3279G was much higher in patients than those in controls. The allele frequency of c.-3279G was also significantly higher in jaundice infants than that in controls $(p=$ 0.006).

Genotype distributions based on the nucleotide at c.-3156 and the TA repeat number are also shown in Table 1 . The genotype distributions based on both polymorphisms in the jaundice and control groups did not shift from HardyWeinberg equilibrium. There were no significant differences in genotype distribution or allele frequency between the groups.

Clinical features among genotypes based on the nucleotide at c.-3279. There was no significant difference in the onset time of hyperbilirubinemia among the newborn infants with the different genotypes. With regard to the duration of hyperbilirubinemia, we were not able to come to any conclusion because phototherapy was given to all the newborn infants with hyperbilirubinemia.

There was no significant difference in mean peak bilirubin levels in jaundice infants among the different genotypes based on the nucleotide at c.-3279: T/T, $23.4 \pm 4.3 \mathrm{mg} / \mathrm{dL}$ (mean \pm $\mathrm{SD}) ; \mathrm{T} / \mathrm{G}, 23.3 \pm 5.1 \mathrm{mg} / \mathrm{dL}$; and $\mathrm{G} / \mathrm{G}, 23.0 \pm 5.0 \mathrm{mg} / \mathrm{dL}$. There was also no significant difference in bilirubin levels in control infants among the different genotypes based on the nucleotide at c. $-3279: \mathrm{T} / \mathrm{T}, 9.8 \pm 2.3 \mathrm{mg} / \mathrm{dL} ; \mathrm{T} / \mathrm{G}, 10.6 \pm 2.0$ $\mathrm{mg} / \mathrm{dL}$; and $\mathrm{G} / \mathrm{G}, 10.9 \pm 1.1 \mathrm{mg} / \mathrm{dL}$.

Haplotype analysis in the UGT1A1 promoter region using PHASE software. Table 2 shows the estimated frequencies of the UGTIAl promoter haplotypes in jaundice and control groups. Three major haplotypes were statistically inferred with a frequency of $>10 \%$ in both groups. With these major haplotypes, the frequency reached a total of $\sim 95 \%$ in each group. However, the haplotype distributions were significantly different from each other $(p=0.016)$. The frequency of

Table 1. Genotype and allele frequencies of UGT1A1 promoter mutations

\begin{tabular}{|c|c|c|c|c|c|c|c|}
\hline & \multicolumn{4}{|c|}{ Genotype frequency } & \multicolumn{3}{|c|}{ Allele frequency } \\
\hline & $\mathrm{T} / \mathrm{T}$ & $\mathrm{T} / \mathrm{G}$ & $\mathrm{G} / \mathrm{G}$ & Total & $\mathrm{T}$ & G & Total \\
\hline \multicolumn{8}{|l|}{ c. $-3279 \mathrm{~T}>\mathrm{G}$} \\
\hline Neonatal jaundice & $19(29 \%)$ & $29(44 \%)$ & $18(27 \%)$ & $66(100 \%)$ & $67(51 \%)$ & $65(49 \%)$ & $132(100 \%)$ \\
\hline \multirow[t]{3}{*}{ Control } & $28(40 \%)$ & $38(54 \%)$ & $4(6 \%)$ & $70(100 \%)$ & $94(67 \%)$ & $46(33 \%)$ & $140(100 \%)$ \\
\hline & & & & $p=0.003$ & & & $p=0.006$ \\
\hline & $\mathrm{G} / \mathrm{G}$ & G/A & $\mathrm{A} / \mathrm{A}$ & Total & G & A & Total \\
\hline \multicolumn{8}{|l|}{ c. $-3156 \mathrm{G}>\mathrm{A}$} \\
\hline Neonatal jaundice & $51(77 \%)$ & $14(21 \%)$ & $1(2 \%)$ & $66(100 \%)$ & $116(88 \%)$ & $16(12 \%)$ & $132(100 \%)$ \\
\hline \multirow[t]{3}{*}{ Control } & $51(73 \%)$ & $16(23 \%)$ & $3(4 \%)$ & $70(100 \%)$ & $118(84 \%)$ & $22(16 \%)$ & $140(100 \%)$ \\
\hline & & & & $p=0.73$ & & & $p=0.39$ \\
\hline & $(\mathrm{TA}) 6$ & $(\mathrm{TA}) 6 /(\mathrm{TA}) 7$ & $(\mathrm{TA}) 7$ & Total & (TA)6 & $(\mathrm{TA}) 7$ & Total \\
\hline \multicolumn{8}{|l|}{ TATA box } \\
\hline Neonatal jaundice & $51(77 \%)$ & $14(21 \%)$ & $1(2 \%)$ & $66(100 \%)$ & $116(88 \%)$ & $16(12 \%)$ & $132(100 \%)$ \\
\hline \multirow[t]{2}{*}{ Control } & $53(76 \%)$ & $16(23 \%)$ & $1(1 \%)$ & $70(100 \%)$ & $122(87 \%)$ & $18(13 \%)$ & $140(100 \%)$ \\
\hline & & & & $p=0.97$ & & & $p=0.85$ \\
\hline
\end{tabular}


Table 2. Estimated frequencies of UGT1A1 promoter mutations in Malay infants

\begin{tabular}{|c|c|c|c|c|c|}
\hline \multicolumn{3}{|c|}{ Position } & \multicolumn{3}{|c|}{ Estimated frequency $(\%)^{*}$} \\
\hline c. -3279 & c. -3156 & TATA box & Jaundice & Control & $p \dagger$ \\
\hline $\mathrm{T}$ & G & (TA) 6 & 50.0 & 66.0 & 0.016 \\
\hline G & G & (TA) 6 & 37.0 & 19.0 & \\
\hline G & A & (TA) 7 & 11.0 & 13.0 & \\
\hline G & A & (TA) 6 & 0.8 & 1.0 & \\
\hline $\mathrm{T}$ & $\mathrm{G}$ & (TA) 7 & 0.8 & 一 & \\
\hline $\mathrm{T}$ & A & (TA) 6 & 一未 & 2.0 & \\
\hline G & G & (TA) 7 & 一 & 一 & \\
\hline $\mathrm{T}$ & A & (TA) 7 & 0.1 & 一 & \\
\hline
\end{tabular}

* UGT1A1 haplotypes were statistically inferred using an algorithm based on Bayesian inference, PHASE version 2.1.1 (http://www.stat.Washington. edu/stephens/).

$\dagger$ Haplotype frequency comparisons between neonatal jaundice and control groups.

$\ddagger$-Not inferred.

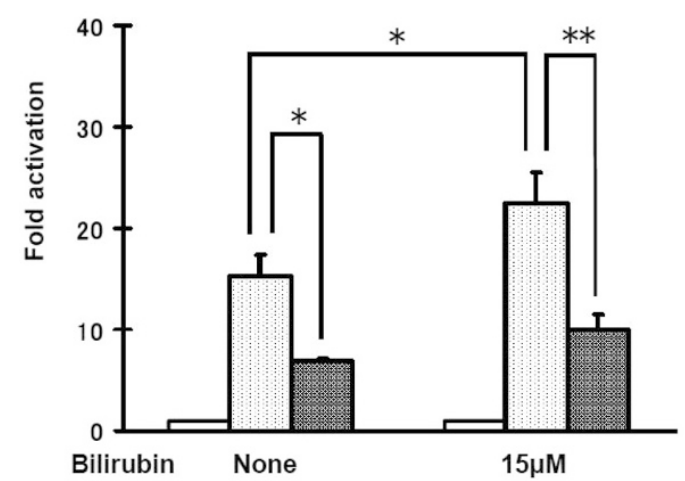

Figure 4. Luciferase reporter assay in HepG2 cells. Transcriptional activity of normal pgtPBREM(-3279T) and mutant pgtPBREM(-3279G) in HepG2 cells was determined in the presence of bilirubin and its possible oxidized product in the medium. The luciferase activity of pGL2-Basic-miniTK was denoted as 1-fold activation. $\square$, pGL2-Basic-miniTK (Mock); $\square$, pgtPBREM (-3279T); and 1.

haplotype [-3279G/-3156G/(TA)6] in the jaundice group was twice that in controls, whereas the frequency of haplotype [-3279G/-3156A/(TA)7] was similar between the groups.

Transcriptional activity assay of normal and mutant pgtPBREMs. First, we determined the transcriptional activity of pgtPBREM(-3279T) and pgtPBREM(-3279G) in HepG2 cells in both the absence and presence of bilirubin (and its possible oxidized product) in the medium. There was a significant difference between the transcriptional activities of both pgtPBREM plasmids ( $p=0.003$ in the absence of bilirubin and $p=0.003$ in the presence of bilirubin) (Fig. 4).

The pgtPBREM(-3279T) promoter was significantly activated by the addition of bilirubin in the medium $(15 \mu \mathrm{M})(p=$ 0.028), whereas the pgtPBREM(-3279G) promoter was not significantly activated (Fig. 4). In the absence of bilirubin, the transcriptional activity of the pgtPBREM(-3279G) promoter was $\sim 50 \%$ of that of the pgtPBREM(-3279T) promoter. In the presence of bilirubin, however, the transcriptional activity of the pgtPBREM(-3279G) promoter was $\sim 40 \%$ of that of the pgtPBREM(-3279T) promoter. These findings suggested that c. $-3279 \mathrm{~T}>\mathrm{G}$ reduced the UGTIAl promoter in response to bilirubin.

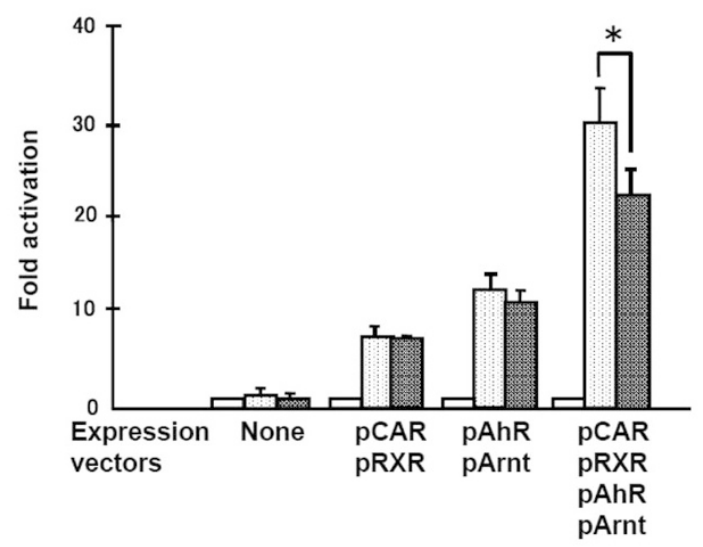

Figure 5. Luciferase reporter assay in COS-7 cells. Transcriptional activity of normal pgtPBREM(-3279T) and mutant pgtPBREM(-3279G) in COS-7 cells was determined in the overexpression status of the nuclear factors, CAR, RXR, AhR, and Arnt. The luciferase activity of pGL2-Basic-miniTK was denoted as 1-fold activation. $\square$, pGL2-Basic-miniTK (Mock); $\square$, pgtPBREM $(-3279 \mathrm{~T})$; and $\mathrm{im}$, pgtPBREM $(-3279 \mathrm{G}) .{ }^{*} p<0.05$.

Second, to determine the effect of the c.-3279T $>$ G mutation on the UGTIAI promoter in nonhepatic cell lines, we determined transcriptional activity of pgtPBREM(-3279T) and pgtPBREM(-3279G) in COS-7 cells. Both promoters were synergistically activated by the overexpression of "CAR + RXR," more activated by the overexpression of "AhR + Arnt," and activated the most by the overexpression of all nuclear factors, CAR + RXR and AhR + Arnt. It should be noted that there was no significant difference between the transcriptional activities of the pgtPBREM(-3279T) and pgtPBREM(-3279G) promoters without overexpression of any nuclear factors. In addition, neither CAR + pRXR nor AhR + Arnt caused a significant difference between the transcriptional activities of both promoters. The transcriptional activity of the pgtPBREM(-3279G) promoter became significantly lower than that of the pgtPBREM(-3279T) promoter when all the nuclear factors, CAR, RXR, AhR, and Arnt, were overexpressed (fold activation difference $=7.5$, Fig. 5). These results suggested that c.-3279T $>\mathrm{G}$ modified the synergistic effects of the nuclear factors.

\section{DISCUSSION}

Association of c.-3279T $>G$ in UGT1A1 with neonatal jaundice. This is the first report of the allele frequency of c.-3279T $>$ G in Malays. According to Innocenti et al.,(10) the allele frequency of c.-3279T $>\mathrm{G}$ is $44 \%$ in whites and $34 \%$ in Asians. Kanai et al. (20) reported the allele frequencies of c. $-3279 \mathrm{~T}>\mathrm{G}$ in several populations as follows: $26 \%$ in Japanese, 33\% in Korean, 30\% in Chinese, and 35\% in German populations. The allele frequency of c.-3279T $>\mathrm{G}$ in Malays, $33 \%$, is similar to previous reports from Asian ethnic groups.

In our study, the allele frequency of c.-3279T $>\mathrm{G}$ in Malay infants with neonatal jaundice (49\%) was more frequent than in those without jaundice (33\%). The number of cases with homozygosity for c.-3279T $>\mathrm{G}$ was much larger in the jaundice group than in controls. These findings suggest that c.3279T $>$ G contributes to neonatal jaundice in Malays. How- 
ever, Kanai et al. (20) reported that there was no significant increase in the allele frequency of c.-3279T $>\mathrm{G}$ in infants with neonatal jaundice compared with that in infants without neonatal jaundice in Japanese. The difference between the studies may reflect differences in the genetic or nongenetic background between the ethnic groups.

Modification of the synergistic effects of nuclear factors by $\boldsymbol{c} . \mathbf{- 3 2 7 9 T}>\boldsymbol{G}$. Using a luciferase reporter assay with HepG2 cells that expressed AhR, we demonstrated that mutant gtPBREM with c.-3279T $>\mathrm{G}$ decreased the transcriptional activity of the UGTIAI promoter. In addition, we demonstrated that the c.-3279T $>\mathrm{G}$ mutation reduced the responsiveness of gtPBREM to bilirubin (and its possible oxidized products). The detailed mechanism of UGT1Al gene activation by bilirubin is not fully understood. Huang et al. (21) demonstrated that bilirubin indirectly stimulates CAR accumulation in the nucleus. Recently, Togawa et al. (22) indicated that bilirubin also stimulates UGT1Al via binding with AhR. These findings suggested that the UGTIAl promoter is activated via nuclear factor binding stimulated by bilirubin. Our results also suggest that c.-3279T $>\mathrm{G}$ has an inhibitory effect on nuclear factor machinery stimulated by bilirubin.

We showed in the luciferase reporter assay using COS-7 cells that when all the nuclear factors, CAR, RXR, AhR, and Arnt, were overexpressed, there was a significant difference in transcriptional activity between normal and mutant pgtPBREM. The c.-3279T $>$ G mutation did not reduce the transcriptional activity of the luciferase-reporter gene in COS-7 cells without overexpression of nuclear factors. Our findings suggest that c.-3279T $>$ G may modify the synergistic effects of the nuclear factors associated with transcription.

However, it is not clear why the c.-3279T $>\mathrm{G}$ mutation reduces transcriptional activity in HepG2 cells without overexpression of nuclear factors, or why the c.-3279T $>$ G mutation does not reduce transcriptional activity in COS-7 cells without overexpression of nuclear factors. Different effects of the same mutation in different cell lines could be explained by the expression conditions of nuclear factors in each cell line.

Combined effects of c.-3279T $>G$ and other mutations in UGT1A1. In our population study, the heterozygous state of the c.-3279T $>\mathrm{G}$ mutation appeared in both the jaundice group and controls. In addition, there were many infants with neonatal jaundice who did not carry the c.-3279T $>$ G mutation. These findings strongly suggest that the presence of the c.$3279 \mathrm{~T}>\mathrm{G}$ mutation in only one allele does not cause neonatal jaundice and that other risk factors are also present in neonatal jaundice group.

On the basis of the PHASE analysis, we expected the high prevalence of a UGT1A1 allele with c.-3279T $>\mathrm{G}$ and A(TA)7TAA in the Malay population (Table 2). Homozygosity for c.-3279T $>\mathrm{G}$ and A(TA)7TAA may be associated with neonatal jaundice and/or GS. Maruo et al. (23) reported that 23 GS patients, including 11 whites and 12 Japanese, were homozygous for c.-3279T $>$ G and A(TA)7TAA. Costa et al. (24) also showed that 67 of 74 GS patients were homozygous for c.-3279T $>\mathrm{G}$ and A(TA)7TAA. Ferraris et al. (25) investigated the role of three UGT1A1 polymorphisms [A(TA)nTAA, c.-3279T $>$ G, and c. $211 \mathrm{G}>\mathrm{A}]$ in the susceptibility to
GS in 53 Italian pediatric subjects compared with 83 unaffected controls. According to Ferraris et al.,(25) homozygosity for both A(TA)7TAA and c.-3279G was associated with the highest relative risk estimate $(\mathrm{OR}=19.23,95 \% \mathrm{CI}=7.34$ 50.4; $p<0.001)$. All these researchers believed that there is a synergistic effect of c.-3279T $>\mathrm{G}$ and A(TA)7TAA and calculated that the association of these two mutations could lower the transcriptional activity of UGTIAI to the GScausing level (23-25).

With regard to mutations in the coding region of UGTIAl, we previously reported that the $\mathrm{c} .211 \mathrm{G}>\mathrm{A}$ mutation is rare in Malays and Javanese $(13,14)$. However, according to recent reports in the Chinese population in Malaysia and Singapore, the $c .211 \mathrm{G}>$ A mutation is observed more frequent than Malays and Javanese (26-28). Thus, it can be expected that the frequency of alleles with c.-3279T $>$ G and c.211G $>$ A may be higher in the Chinese (or East Asian) population than in the Malay and Javanese populations. The combined effects of c. $-3279 \mathrm{~T}>\mathrm{G}$ and c. $211 \mathrm{G}>\mathrm{A}$ may contribute greatly to the development of GS or neonatal jaundice.

Combined effects of c.-3279T $>G$ in UGT1A1 and mutations in other genes. There are several reports in cases with an inherited UGTIAl deficiency and genetic hemolytic disorders such as G6PD deficiency $(29,30)$. They are good examples of combined effects of mutations of UGTIAl and other genes. Recently, two other proteins related to neonatal jaundice have been investigated with regard to overflow of nonconjugated bilirubin from the liver; transporter proteins of bilirubin in hepatic cells encoded by the organic anion transporter 2 gene (OATP2 or SLC21A6) $(31,32)$ and the glutathione-Stransferase gene (GST) $(33,34)$. However, combined effects of c.-3279T $>\mathrm{G}$ in UGTIAl and hemolytic disorder-causing genes and combined effects of c.-3279T $>\mathrm{G}$ and $O A T P 2$ (or $G S T)$ mutations remain to be clarified.

Combined effects of c.-3279T>G in UGT1A1 and environmental factors. It is well known that breast feeding increases serum bilirubin levels (35). Maruo et al. (36) demonstrated that the c.211G $>$ A mutation is commonly found in infants with unconjugated hyperbilirubinemia because of breast milk feeding in the Japanese population. Similarly, we can expect some combined effects of c.-3279T $>\mathrm{G}$ and breast milk feeding on the development of neonatal jaundice, although we could not compare infants fed with breast milk and those fed with formula milk in this study.

Mutations in the UGT1A1 promoter and maturation of UGT1A1 enzyme activity. Neonatal jaundice is associated with the maturation of UGTIAl enzyme activity. Kawade and Onishi (37) reported that UGTIAl enzyme activity toward bilirubin changes with age. They showed that the activities of the middle fetal, neonatal, and early infantile phases are $\sim 0.1$, $0.1-1$, and $1-100 \%$, respectively, of the mature-phase values (37). It is likely that the maturation mechanisms of UGT1AI activity are associated with the pathway activating the UGTIA1 promoter. Combination of cis- or trans-acting factors analysis of the UGTIAl promoter may offer a clue to understanding the maturation mechanisms of UGTIAl activity. 


\section{CONCLUSIONS}

In the Malay population, c.-3279T $>\mathrm{G}$ in UGT1Al is a genetic risk factor for neonatal jaundice. Luciferase reporter assay in HepG2 cells indicated that the c.-3279T $>$ G mutation reduces the responsiveness of UGTIAl transcription to bilirubin. In addition, luciferase reporter assay in COS-7 cells suggested that c.-3279T $>$ G modifies the synergistic effects of the nuclear factors which are associated with the transcription.

Acknowledgments. We thank the neonatal ward staffs in the Hospital of University Sains Malaysia, and infants and their parents for their willing participation in our study.

\section{REFERENCES}

1. Seppen J, Bosma PJ, Goldhoorn BG, Bakker CT, Chowdhury JR, Chowdhury NR, Jansen PL, Oude Elferink RP 1994 Discrimination between Crigler-Najjar type I and II by expression of mutant bilirubin uridine diphosphate-glucuronosyltransferase. J Clin Invest 94:2385-2391

2. Kadakol A, Ghosh SS, Sappal BS, Sharma G, Chowdhury JR, Chowdhury NR 2000 Genetic lesions of bilirubin uridine-diphosphoglucuronate glucuronosyltransferase (UGT1A1) causing Crigler-Najjar and Gilbert syndromes: correlation of genotype to phenotype. Hum Mutat 16:297-306

3. Bosma PJ, Chowdhury JR, Bakker C, Gantla S, de Boer A, Oostra BA, Lindhout D, Tytgat GN, Jansen PL, Oude Elferink RP, Chowdhury NR 1995 The genetic basis of the reduced expression of bilirubin UDP-glucuronosyltransferase 1 in Gilbert's syndrome. N Engl J Med 333:1171-1175

4. Monaghan G, Ryan M, Seddon R, Hume R, Burchell B 1996 Genetic variation in bilirubin UPD-glucuronosyltransferase gene promoter and Gilbert's syndrome. Lancet 347:578-581

5. Ciotti M, Chen F, Rubaltelli FF, Owens IS 1998 Coding defect and a TATA box mutation at the bilirubin UDP-glucuronosyltransferase gene cause Crigler-Najjar type I disease. Biochim Biophys Acta 1407:40-50

6. Bancroft JD, Kreamer B, Gourley GR 1998 Gilbert syndrome accelerates development of neonatal jaundice. J Pediatr 132:656-660

7. Beutler E, Gelbart T, Demina A 1998 Racial variability in the UDPglucuronosyltransferase 1 (UGT1Al) promoter: a balanced polymorphism for regulation of bilirubin metabolism? Proc Natl Acad Sci USA 95:8170-8174

8. Akaba K, Kimura T, Sasaki A, Tanabe S, Ikegami T, Hashimoto M, Umeda H, Yoshida H, Umetsu K, Chiba H, Yuasa I, Hayasaka K 1998 Neonatal hyperbilirubinemia and mutation of the bilirubin uridine diphosphate-glucuronosyltransferase gene: a common missense mutation among Japanese, Koreans and Chinese. Biochem Mol Biol Int 46:21-26

9. Sugatani J, Yamakawa K, Yoshinari K, Machida T, Takagi H, Mori M, Kakizaki S, Sueyoshi T, Negishi M, Miwa M 2002 Identification of a defect in the UGT1A1 gene promoter and its association with hyperbilirubinemia. Biochem Biophys Res Commun 292:492-497

10. Innocenti F, Liu W, Chen P, Desai AA, Das S, Ratain MJ 2005 Haplotypes of variants in the UDP-glucuronosyltransferase1A9 and 1A1 genes. Pharmacogenet Genomics 15:295-301

11. Sugatani J, Kojima H, Ueda A, Kakizaki S, Yoshinari K, Gong QH, Owens IS, Negishi M, Sueyoshi T 2001 The phenobarbital response enhancer module in the human bilirubin UDP-glucuronosyltransferase UGT1A1 gene and regulation by the nuclear receptor CAR. Hepatology 33:1232-1238

12. Sai K, Saeki M, Saito Y, Ozawa S, Katori N, Jinno H, Hasegawa R, Kaniwa N, Sawada J, Komamura K, Ueno K, Kamakura S, Kitakaze M, Kitamura Y, Kamatani N, Minami H, Ohtsu A, Shirao K, Yoshida T, Saijo N 2004 UGT1Al haplotypes associated with reduced glucuronidation and increased serum bilirubin in irinotecanadministered Japanese patients with cancer. Clin Pharmacol Ther 75:501-515

13. Yusoff S, Van Rostenberghe H, Yusoff NM, Talib NA, Ramli N, Ismail NZ, Ismail WP, Matsuo M, Nishio H 2006 Frequencies of A(TA)7TAA, G71R, and G493R mutations of the UGT1A1 gene in the Malaysian population. Biol Neonate 89:171176

14. Sutomo R, Talib NA, Yusoff NM, Van Rostenberghe H, Sadewa AH, Sunarti, Sofro AS, Yokoyama N, Lee MJ, Matsuo M, Nishio H 2004 Screening for G71R mutation of the UGT1A1 gene in the Javanese-Indonesian and Malay-Malaysian populations. Pediatr Int 46:565-569

15. Gibbs RA, Nguyen PN, Caskey CT 1989 Detection of single DNA base differences by competitive oligonucleotide priming. Nucleic Acids Res 17:2437-2448

16. Stephens M, Smith NJ, Donnelly P 2001 A new statistical method for haplotype reconstruction from population data. Am J Hum Genet 68:978-989

17. Niu T 2004 Algorithms for inferring haplotypes. Genet Epidemiol 27:334-347

18. Sugatani J, Mizushima K, Osabe M, Yamakawa K, Kakizaki S, Takagi H, Mori M, Ikari A, Miwa M 2008 Transcriptional regulation of human UGT1Al gene expression through distal and proximal promoter motifs: implication of defects in the UGT1A1 gene promoter. Naunyn Schmiedebergs Arch Pharmacol 377:597-605

19. Yueh MF, Huang YH, Hiller A, Chen S, Nguyen N, Tukey RH 2003 Involvement of the xenobiotic response element (XRE) in Ah receptor-mediated induction of human UDP-glucuronosyltransferase 1A1. J Biol Chem 278:15001-15006

20. Kanai M, Kijima K, Shirahata E, Sasaki A, Akaba K, Umetsu K, Tezuka N, Kurachi H, Aikawa S, Hayasaka K 2005 Neonatal hyperbilirubinemia and the bilirubin uridine diphosphate-glucuronosyltransferase gene: the common-3263T > G mutation of phenobarbital response enhancer module is not associated with the neonata hyperbilirubinemia in Japanese. Pediatr Int 47:137-141

21. Huang W, Zhang J, Chua SS, Qatanani M, Han Y, Granata R, Moore DD 2003 Induction of bilirubin clearance by the constitutive androstane receptor (CAR). Proc Natl Acad Sci USA 100:4156-4161

22. Togawa H, Shinkai S, Mizutani T 2008 Induction of human UGT1A1 by bilirubin through AhR dependent pathway. Drug Metab Lett 2:231-237

23. Maruo Y, D'Addario C, Mori A, Iwai M, Takahashi H, Sato H, Takeuchi Y 2004 Two linked polymorphic mutations (A(TA)7TAA and T-3279G) of UGT1A1 as the principal cause of Gilbert syndrome. Hum Genet 115:525-526

24. Costa E, Vieira E, Dos Santos R 2005 The polymorphism c.-3279T $>$ G in the phenobarbital-responsive enhancer module of the bilirubin UDP-glucuronosyltransferase gene is associated with Gilbert syndrome. Clin Chem 51:2204-2206

25. Ferraris A, D'Amato G, Nobili V, Torres B, Marcellini M, Dallapiccola B 2006 Combined test for UGT1A1-3279T->G and A(TA)nTAA polymorphisms best predicts Gilbert's syndrome in Italian pediatric patients. Genet Test 10:121-125

26. Boo NY, Wong FL, Wang MK, Othman A 2009 Homozygous variant of UGT1Al gene mutation and severe neonatal hyperbilirubinemia. Pediatr Int 51:488-493

27. Wong FL, Wang MK, Boo NY, Hamidah NH, Ainoon BO 2007 Rapid detection of the UGT1Al single nucleotide polymorphism G211A using real-time PCR with Taqman minor groove binder probes. J Clin Lab Anal 21:167-172

28. Zhou YY, Lee LY, Ng SY, Hia CP, Low KT, Chong YS, Goh DL 2009 UGTIAI haplotype mutation among Asians in Singapore. Neonatology 96:150-155

29. Kaplan M, Renbaum P, Vreman HJ, Wong RJ, Levy-Lahad E, Hammerman C, Stevenson DK 2007 (TA)n UGT 1A1 promoter polymorphism: a crucial factor in the pathophysiology of jaundice in G-6-PD deficient neonates. Pediatr Res 61:727-731

30. Huang CS, Chang PF, Huang MJ, Chen ES, Chen WC 2002 Glucose-6-phosphate dehydrogenase deficiency, the UDP-glucuronosyl transferase $1 \mathrm{~A} 1$ gene, and neonatal hyperbilirubinemia. Gastroenterology 123:127-133

31. Cui Y, Konig J, Leier I, Buchholz U, Keppler D 2001 Hepatic uptake of bilirubin and its conjugates by the human organic anion transporter SLC21A6. J Biol Chem 276:9626-9630

32. Huang MJ, Kua KE, Teng HC, Tang KS, Weng HW, Huang CS 2004 Risk factors for severe hyperbilirubinemia in neonates. Pediatr Res 56:682-689

33. Zucker SD, Goessling W, Ransil BJ, Gollan JL 1995 Influence of glutathione S-transferase B (ligandin) on the intermembrane transfer of bilirubin. Implications for the intracellular transport of nonsubstrate ligands in hepatocytes. J Clin Invest 96:1927-1935

34. Akizawa E, Koiwai K, Hayano T, Maezawa S, Matsushita T, Koiwai O 2008 Direct binding of ligandin to uridine $5^{\prime}$-diphosphate glucuronosyltransferase 1A1. Hepatol Res 38:402-409

35. Gourley GR, Arend RA $1986 \beta$-Glucuronidase and hyperbilirubinaemia in breastfed and formula-fed babies. Lancet 1:644-646

36. Maruo Y, Nishizawa K, Sato H, Sawa H, Shimada M 2000 Prolonged unconjugated hyperbilirubinemia associated with breast milk and mutations of the bilirubin uridine diphosphate-glucuronosyltransferase gene. Pediatrics 106:E59

37. Kawade N, Onishi S 1981 The prenatal and postnatal development of UDPglucuronyltransferase activity towards bilirubin and the effect of premature birth on this activity in the human liver. Biochem J 196:257-260 